\title{
The efficacy and safety of percutaneous balloon angioplasty for aortic coarctation in children
}

\section{Acute and mid-term results in a single center experience}

Saad Q. Khoshhal, MBBS, SBFM, Mansour B. Al-Mutairi, MBBS, SBFM, Abdulhameed A. Alnajjar, MBBS, SBFM,

Mohamed M. Morsy, MD, PHD, Sherif Salem, MD, PHD, Aseel A. Salmi, MBBS, SBFM, Khaled M. El-Harbi, MBBS, SBFM,

Hany M. Abo-Haded, MD, PhD.

\begin{abstract}

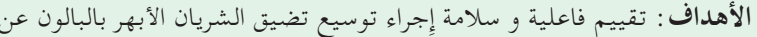

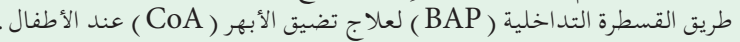

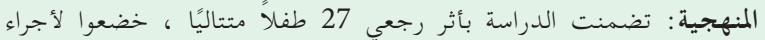

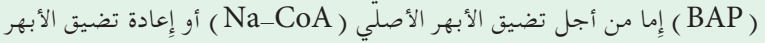

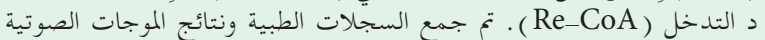

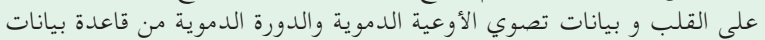

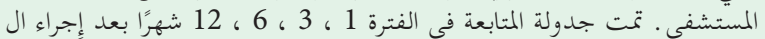

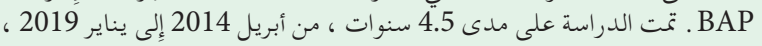

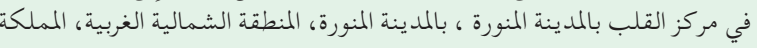

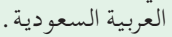

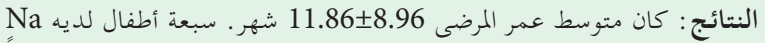

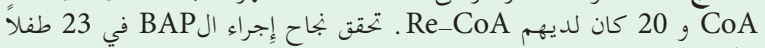

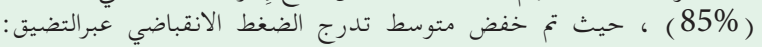

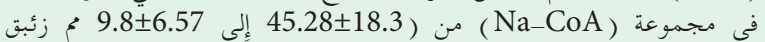
،

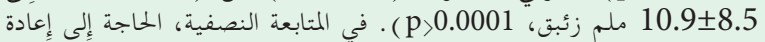

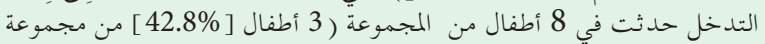

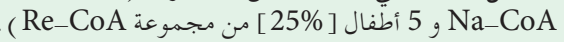

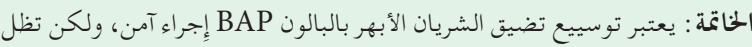

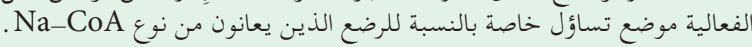

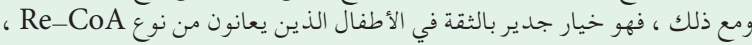

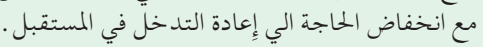

Objectives: To assess the efficacy and safety of balloon angioplasty (BAP) procedure for treatment of coarctation of the aorta $(\mathrm{CoA})$ in children.

Methods: A retrospective study included 27 consecutive children, underwent BAP for either native- $\mathrm{CoA}(\mathrm{Na}-$ CoA) or recoarctation (Re-CoA). Medical records, echocardiographic findings, angiographic and hemodynamic data were collected from the hospital database. Follow-up was scheduled at 1, 3, 6, 12 months after the procedure. The study took place over a period of 4.5 years, from April 2014 to January 2019, in Madinah Cardiac Center, Madinah, Northwest region, Saudi Arabia.
Results: The mean age of patients was $11.86 \pm 8.96$ months. Seven children had $\mathrm{Na}-\mathrm{CoA}$ and 20 children had Re-CoA. The success rate of the procedure was achieved in 23 children (85\%), as BAP reduced the mean systolic pressure gradient across the $\mathrm{CoA}(\mathrm{Na}-\mathrm{CoA}$ : from $45.28 \pm 18.3$ to $9.8 \pm 6.57 \mathrm{~mm} \mathrm{Hg}, p=0.0009$ ), and in Re-CoA groups (from $42.48 \pm 16.7$ to $10.9 \pm 8.5$ $\mathrm{mm} \mathrm{Hg}, p<0.0001)$. In mid-term follow-up, the need for re-intervention occurred in 8 children of the cohort (3 children $[42.8 \%]$ from the $\mathrm{Na}-\mathrm{CoA}$ group, and 5 children [25\%] from the Re-CoA group).

Conclusions: Balloon angioplasty is considered a safe procedure for the management of CoA, but its efficacy remains questionable especially for young infants with $\mathrm{Na}-\mathrm{CoA}$ type. However, it is a reliable option for managing Re-CoA children, with a lower rate of future re-intervention.

Keywords: coarctation of the aorta, balloon angioplasty, children, follow-up studies

$$
\begin{array}{r}
\text { Saudi Med J 2020; Vol. } 41 \text { (11): 1252-1258 } \\
\text { doi: 10.15537/smj.2020.11.25452 }
\end{array}
$$

From the Department of Pediatrics (Khoshhal, El-Harbi, Abo-Haded), Faculty of Medicine, Taibah University; from the Department of Pediatric Cardiology (Al-Mutairi, Alnajjar, Morsy, Salem, Salmi), Madinah Cardiac Center, Madinah, Kingdom of Saudi Arabia; from the Department of Pediatrics (Morsy), Faculty of Medicine, Sohag University, Sohag; from the Department of Pediatrics (Salem), Faculty of Medicine, Menoufiya University, Menoufiya; and from the Pediatric Cardiology Unit (Abo-Haded), Department of Pediatrics, Faculty of Medicine, Mansoura University, Mansoura, Egypt.

Received 24th June 2020. Accepted 29th September 2020.

Address correspondence and reprint request to: Dr. Hany M. Abo-Haded, Department of Pediatrics, Faculty of Medicine, Taibah University, Madinah, Kingdom of Saudi Arabia.E-mail: hany_haded@yahoo.com ORCID ID: https://orcid.org/0000-0003-1343-9031 
$\mathrm{C}$ oarctation of the aorta $(\mathrm{CoA})$ is the sixth most common congenital heart disease in children representing $4-6 \%$ of live births with isolated congenital heart diseases. ${ }^{1}$ The most common type of CoA in children is the native type $(\mathrm{Na}-\mathrm{CoA})$, which refers to a localized narrowing of the descending aorta opposite to the insertion of the ductus arteriosus. ${ }^{2}$ The established treatment options of CoA include surgery; and catheter interventional techniques: balloon angioplasty (BAP), and endoluminal stent implantation. ${ }^{3}$ Surgery is the favored treatment of neonates and young infants (age below 4-months) diagnosed to have $\mathrm{Na}$-CoA; with a lower risk for re-intervention in comparison with balloon angioplasty. ${ }^{4}$ In older infants and children (between 4 -months to 5-years age, and weight $<25 \mathrm{~kg}$ ), BAP is safe and successful procedure if the lesion is discrete and there is no evidence of arch hypoplasia; while in older children ( $>5$ years old and weight $<25 \mathrm{~kg}$ ) stenting has become the favored approach in many centers. ${ }^{3}$ The most common complication following CoA repair (either surgical or catheter-based) is recoarctation (Re-CoA), which refers to restenosis after an initially successful BAP, or after surgical repair. ${ }^{5}$ The incidence of recurrence of CoA following initial management tend to be higher following BAP especially if carried out in younger age, low patient weight, or in the presence of transverse arch hypoplasia. Other complications are arterial hypertension and/or aneurysms at the site of intervention. ${ }^{6}$

The role of the distinctive treatment alternatives is still a matter of questionable debate. ${ }^{7,8}$ This study aimed to report our experience, and assess the safety and effectiveness (immediate and mid-term results) of $\mathrm{BAP}$ in children for treating $\mathrm{Na}-\mathrm{CoA}$ and $\mathrm{Re}-\mathrm{CoA}$ in our center.

Methods. This retrospective observational study was conducted in Madinah Cardiac Center (MCC), Al-Madinah, Northwest, Saudi Arabia, between April 2014 and January 2019. Children diagnosed with $\mathrm{Na}-\mathrm{CoA}$ or Re-CoA in this region are routinely referred to MCC for cardiac assessment and management. The inclusion criteria comprised: i) systolic blood pressure gradient $>20 \mathrm{~mm} \mathrm{Hg}$ between arms and legs, ii) an arterial hypertension of the upper extremities at rest or during exercise, iii) signs of decreased left ventricular

Disclosure. Authors have no conflict of interests, and the work was not supported or funded by any drug company. function, or signs of left ventricular hypertrophy in echocardiography, and iv) associative minor cardiac anomalies, namely, atrial septal defect (ASD), small ventricular septal defect (VSD), patent foramen ovale (PFO), or mild aortic valve stenosis. The exclusion criteria comprised: children diagnosed with CoA but associated with other major cardiac anomalies, namely, severe hypoplastic aortic arch anomalies.

The study population was categorized as " $\mathrm{Na}-\mathrm{CoA}$ group" if they were initially diagnosed in our center with $\mathrm{CoA}$, while they were categorized as "Re-CoA group" if they experienced any CoA repair techniques outside our center with different managing protocols.

Medical records, echocardiographic findings, angiographic and hemodynamic data of all consecutive children referred for having $\mathrm{Na}-\mathrm{CoA}$ or $\mathrm{Re}-\mathrm{CoA}$ during the study period were retrieved and included in the study. We compared our CoA cohort results with other internationally published cohorts to assess our experience.

Informed consent from included participants and/or their parents was obtained. The study was conducted in accordance with the principles of the Helsinki Declaration and was approved by the Ethical Committee Board of MCC (Reference no. MCC201913), Madinah, Saudi Arabia.

Procedure. The catheter BAP intervention were conducted under general anesthesia. Percutaneous femoral artery access was carried out, and a $4 \mathrm{~F}$ introducer sheath was inserted. The CoA segment was crossed in a retrograde approach using combined $4 \mathrm{~F}$ multipurpose catheter (Infinity, Cordis, Santa Clara, CA, USA) and a soft guidewire (Radifocus, Terumo Corporation). Peak pressure gradients between the ascending aorta (AAO) and the descending aorta (DAO) were estimated. Thus, the multipurpose catheter was exchanged to a $4 \mathrm{~F}$ pigtail catheter (Infinity, Cordis, Santa Clara, CA, USA) to be placed in the AAO. Biplane angiography of the CoA (left anterior oblique $20^{\circ}$ and lateral projections $90^{\circ}$ ) was recorded. The following measurements were performed in both radiographic planes: diameter of the transverse aortic arch; narrowest diameter of the CoA; and diameter of the DAO (proximally and distally to the site of CoA).

For BAP, high-pressure Sterling ${ }^{\mathrm{TM}}$ balloon dilatation catheters (Boston Scientific, Natick, MA, USA) were used. The size of the first used dilatation balloon was limited to a diameter 2-3 times greater than the diameter of the stenotic segment of the CoA, but not more than the diameter of the distal DAO. At least 2-times dilatation was performed until the balloon waist (CoA segment) disappeared with balloon inflation 

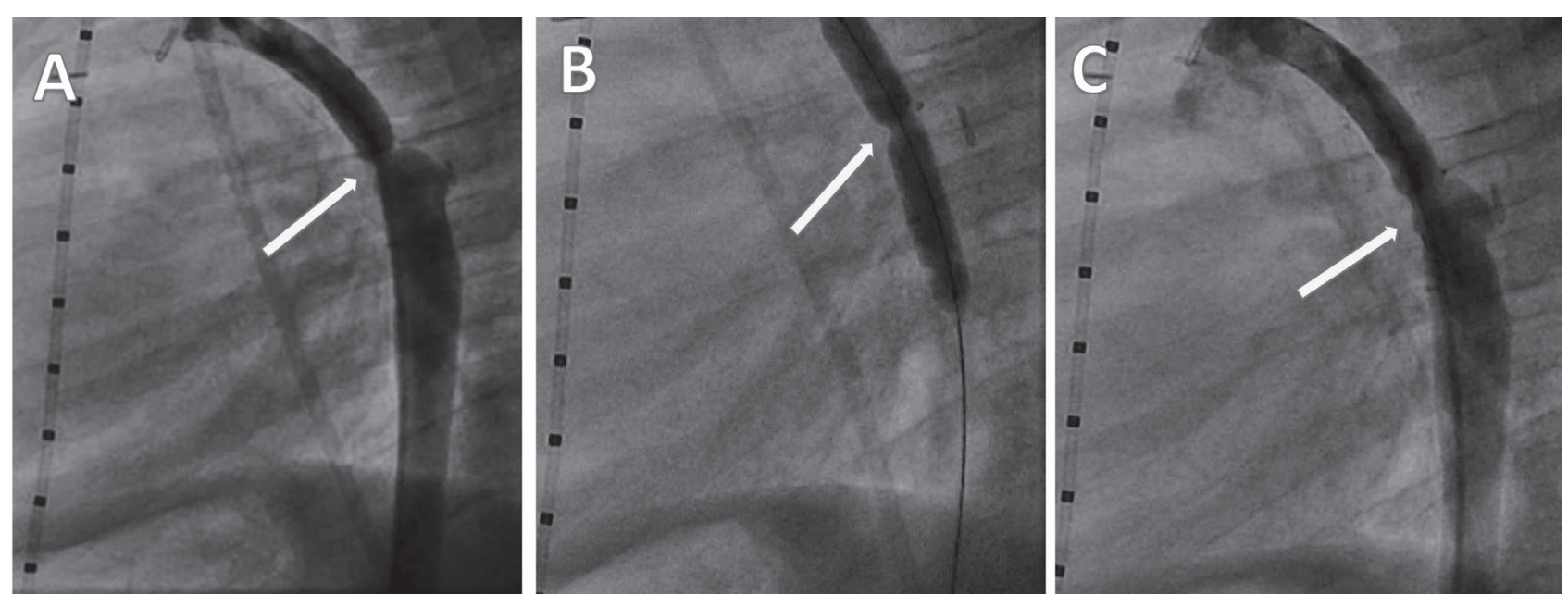

Figure 1 - Ascending aorta angiogram showing A) pre-BAP procedure showing localized narrowing of the descending aorta, B) during balloon dilatation, C) post-BAP showing improvement of the coarctation of the aorta CoA diameter. BAP: balloon angioplasty, COA: coarctation of the aorta

up to the maximum burst pressure, Figure 1. After $\mathrm{BAP}$, the angiography was repeated and the residual invasive pressure gradient from the $\mathrm{AAO}$ to the $\mathrm{DAO}$ was measured. The intervention was terminated when achieving a significant improvement of the CoA diameter and reduction of the pressure gradient $(\leq 10 \mathrm{~mm} \mathrm{Hg})$, or if a major complication occurred (namely, aortic dissection, or aneurysm formation). One day following the procedure, the patient was discharged after focused clinical and echocardiographic evaluations.

Follow-up. A scheduled follow-up at 1, 3, 6, 12 months after the procedure was maintained for all patients; in which clinical assessment of the blood pressure gradient between upper (UL) and lower limbs (LL), and full echocardiography examination was performed for pressure gradients changes or the development of aneurysms.

Statistical analysis. Data were analyzed using IBM SPSS Statistics for Windows, version 20 (IBM Corp., Armonk, N.Y., USA). Quantitative data were expressed as mean \pm standard deviation (SD). Qualitative data were expressed as frequency and percentage. A pairedsamples student t-test was used to compare the values pre- and post- BAP procedure. The associations with $p$-values $\leq 0.05$ were considered statistically significant.

Results. Clinico-demographic and echocardiographic findings. During the study period, 27 children fulfilled the selection criteria and underwent percutaneous BAP. There were 15 males (55.5\%) and 12 females (44.5\%), the mean age of the study population at the time of the intervention was $11.86 \pm 8.96$ months (range:
0.3 - 48 months), mean body weight $7.48 \pm 4.7 \mathrm{Kg}$ (range: $2.27-23.8 \mathrm{~kg}$ ). According to the policy of our center and for the sake of measuring our immediate and midterm results, 7 children were categorized as $\mathrm{Na}-\mathrm{CoA}$ groupwho were diagnosed initially in our center. The remaining 20 children were categorized as Re-CoA group who were referred to our center from other centers after experiencing different $\mathrm{CoA}$ repair techniques and different managing protocols (12 patients following CoA repair surgery and 8 patients after catheter-based $\mathrm{BAP})$. The types of the initial CoA repair surgeries were as follows: an end-to-end anastomosis in 6 patients (50\%), an aortic arch patch reconstruction in 5 patients $(41.7 \%)$, and a subclavian artery flap in one patient $(8.3 \%)$.

The study population demographic characteristics, and pre-intervention clinical data, and echocardiography findings of $\mathrm{Na}-\mathrm{CoA}$ and $\mathrm{Re}-\mathrm{CoA}$ groups are presented in Table 1. Echocardiographic examination of the studied population showed that the isolated discrete narrowing was a finding in the majority of children of $\mathrm{Na}-\mathrm{CoA}$ group ( 5 children), only one child was associated with small VSD, and the other child was associated with small PDA. Though in the Re-CoA group, there was a constant association with an intracardiac defect; VSD $(n=9)$, ASD $(n=4)$, PFO $(n=2)$, PDA $(n=2)$, bicuspid aortic valve with mild stenosis $(\mathrm{n}=2)$, and subaortic fibromuscular ridge $(\mathrm{n}=1)$.

Immediate procedural results. Balloon angioplasty was considered successful when the CoA segment was improved in size on repeated angiography, and the residual pressure gradient from the $\mathrm{AAO}$ to the $\mathrm{DAO}$ 
Table 1 - Demographic characteristics, pre-intervention clinical data, echocardiographic findings, of the studied groups.

\begin{tabular}{|c|c|c|c|}
\hline Data & $\begin{array}{c}\mathrm{Na}-\mathrm{CoA} \\
(\mathrm{n}=7)\end{array}$ & $\begin{array}{c}\mathrm{Re}-\mathrm{CoA} \\
(\mathrm{n}=20)\end{array}$ & $P$-value \\
\hline \multicolumn{4}{|c|}{ Demographic characteristics } \\
\hline $\begin{array}{l}\text { Gender (\%) } \\
\quad \text { Male } \\
\text { Female }\end{array}$ & $\begin{array}{l}5(71.4) \\
2(28.6)\end{array}$ & $\begin{array}{l}11(55) \\
9(45)\end{array}$ & $\begin{array}{l}0.0586 \\
0.0089^{*}\end{array}$ \\
\hline $\begin{array}{l}\text { Age (months) } \\
\text { Mean } \pm \text { SD } \\
\text { Range }\end{array}$ & $\begin{array}{c}13.16 \pm 3.69) \\
1.5-30\end{array}$ & $\begin{array}{c}12.38 \pm 4.39 \\
0.3-48\end{array}$ & 0.6783 \\
\hline $\begin{array}{l}\text { Weight }(\mathrm{Kg}) \\
\text { Mean } \pm \mathrm{SD} \\
\text { Range }\end{array}$ & $\begin{array}{l}7.33 \pm 3.36 \\
2.2-19.6\end{array}$ & $\begin{array}{l}6.7 \pm 3.98 \\
3.6-23.8\end{array}$ & 0.7119 \\
\hline Height $(\mathrm{cm})($ mean $\pm \mathrm{SD})$ & $71.56 \pm 13.07$ & $66.23 \pm 17.31$ & 0.4660 \\
\hline BSA (mean \pm SD) & $0.37 \pm 0.17$ & $0.32 \pm 0.1$ & 0.3540 \\
\hline \multicolumn{4}{|l|}{ Clinical data } \\
\hline $\begin{array}{l}\text { HR }(\text { beat } / \mathrm{min}) \\
(\text { mean } \pm S D)\end{array}$ & $109.0 \pm 8.29$ & $114.0 \pm 8.37$ & 0.1849 \\
\hline $\begin{array}{l}\mathrm{RA}-\mathrm{Bp}(\mathrm{mm} \mathrm{Hg}) \\
(\mathrm{mean} \pm \mathrm{SD})\end{array}$ & $118.33 \pm 24.23$ & $105.45 \pm 18.92$ & 0.1614 \\
\hline $\begin{array}{l}\mathrm{LL}-\mathrm{Bp}(\mathrm{mmHg}) \\
(\mathrm{mean} \pm \mathrm{SD})\end{array}$ & $78.67 \pm 16.94$ & $75.81 \pm 14.32$ & 0.6677 \\
\hline $\begin{array}{l}\text { Bp gradient }(\mathrm{mmHg}) \\
(\text { mean } \pm \mathrm{SD})\end{array}$ & $40.26 \pm 17.58$ & $35.98 \pm 17.34$ & 0.5803 \\
\hline \multicolumn{4}{|l|}{ Echocardiographic findings } \\
\hline FS \% $($ mean $\pm S D)$ & $37.89 \pm 5.67$ & $36.21 \pm 4.92$ & 0.4611 \\
\hline $\begin{array}{l}\text { Peak Doppler systolic } \\
\text { gradient }(\text { mean } \pm S D)\end{array}$ & $56.94 \pm 21.49$ & $47.64 \pm 22.75$ & 0.9519 \\
\hline $\begin{array}{l}\text { Diameter of the } \\
\text { CoA segment }(\mathrm{mm}) \\
(\mathrm{mean} \pm \mathrm{SD})\end{array}$ & $3.8 \pm 0.9$ & $4.2 \pm 0.8$ & 0.2801 \\
\hline \multicolumn{4}{|c|}{$\begin{array}{c}\text { BSA: body surface area, HR: heart rate, RA-Bp: right arm blood pressure } \\
\text { LL-Bp: left leg blood pressure, FS: fractional shortening, } \\
\text { Na-CoA: native-coarctation of the aorta, } \\
\text { Re-CoA: recoarctation-coarctation of the aorta }\end{array}$} \\
\hline
\end{tabular}

is reduced to be $\leq 10 \mathrm{~mm} \mathrm{Hg}$. In our study, 23 children $(85 \%)$ of the whole cohort achieved this success rate (5 patients [71.4\%] from the $\mathrm{Na}-\mathrm{CoA}$ group, and 18 patients [90\%] from the Re-CoA group). In $\mathrm{Na}-\mathrm{CoA}$ group, BAP significantly improved the mean invasive measured peak systolic pressure gradient across the CoA segment (from $45.28 \pm 18.3$ to $9.8 \pm 6.5 \mathrm{~mm} \mathrm{Hg}$, $p=0.0009$ ), and increased the mean diameter of the CoA stenotic segment by approximately $41 \%$ (from $3.4 \pm 0.8$ to $4.8 \pm 1.2 \mathrm{~mm}, p=0.0246$ ). Regarding the Re-CoA group, BAP reduced the mean peak systolic pressure gradient across the CoA stenotic segment (from $42.48 \pm 16.7$ to $10.9 \pm 8.5 \mathrm{mmHg}, p<0.0001$ ), and increased the mean diameter of the CoA stenotic
Table 2 - Immediate balloon angioplasty (BAP) procedure data.

\begin{tabular}{|c|c|c|c|}
\hline Data & $\begin{array}{c}\mathrm{Na}-\mathrm{CoA} \\
(\mathbf{n}=7)\end{array}$ & $\begin{array}{c}\mathrm{Re}-\mathrm{CoA} \\
(\mathrm{n}=20)\end{array}$ & $P$-value \\
\hline \multicolumn{4}{|l|}{ Pre-BAP } \\
\hline $\begin{array}{l}\text { Peak systolic gradient } \\
(\mathrm{mmHg})(\text { mean } \pm \text { SD })\end{array}$ & $45.28 \pm 18.3^{*, *}$ & $42.48 \pm 16.7^{\ddagger, \#}$ & 0.7124 \\
\hline $\begin{array}{l}\text { Diameter of the CoA } \\
\text { segment }(\mathrm{mm})(\text { mean } \pm \mathrm{SD})\end{array}$ & $3.4 \pm 0.8^{\dagger, S}$ & $3.6 \pm 0.5^{* *, \#}$ & 0.4445 \\
\hline $\begin{array}{l}\text { Diameter of transverse } \\
\text { aortic } \operatorname{arch}(\mathrm{mm}) \\
(\mathrm{mean} \pm \mathrm{SD})\end{array}$ & $7.4 \pm 2.5$ & $7.6 \pm 3.1$ & 0.8792 \\
\hline $\begin{array}{l}\text { Diameter of descending } \\
\text { aorta }(\mathrm{mm})(\text { mean } \pm \text { SD })\end{array}$ & $6.4 \pm 1.5$ & $6.5 \pm 2.1$ & 0.9090 \\
\hline \multicolumn{4}{|l|}{ Post-BAP } \\
\hline $\begin{array}{l}\text { Peak systolic gradient } \\
(\mathrm{mmHg})(\text { mean } \pm \text { SD })\end{array}$ & $9.8 \pm 6.5^{*}$ & $10.9 \pm 8.5^{\ddagger, \#}$ & 0.7587 \\
\hline $\begin{array}{l}\text { Diameter of the CoA } \\
\text { segment }(\mathrm{mm})(\text { mean } \pm S D)\end{array}$ & $4.8 \pm 1.2^{\dagger, \S}$ & $4.9 \pm 0.7$ & 0.7903 \\
\hline $\begin{array}{l}\text { Mean diameter improvement } \\
\text { in } \mathrm{mm}(\%)\end{array}$ & $1.4 \pm 41$ & $1.3 \pm 36$ & 0.5193 \\
\hline $\begin{array}{l}\text { Diameter of transverse aortic } \\
\operatorname{arch}(\mathrm{mm})(\operatorname{mean} \pm \mathrm{SD})\end{array}$ & $7.6 \pm 2.8$ & $7.8 \pm 2.7$ & 0.8686 \\
\hline $\begin{array}{l}\text { Diameter of descending aorta } \\
(\mathrm{mm})(\mathrm{mean} \pm \mathrm{SD})\end{array}$ & $6.5 \pm 1.7$ & $6.6 \pm 2.4$ & 0.9203 \\
\hline \multicolumn{4}{|c|}{$\begin{array}{c}* \text { comparison of peak systolic gradient between pre-BAP and post-BAP } \\
\text { in Na-CoA group ( } p=0.0 .0009), \uparrow \text { comparison of diameter of the CoA } \\
\text { segment between Pre-BAP and Post-BAP in Na-CoA group }(p=0.0246) \text {, } \\
{ }^{*} \text { comparison of peak systolic gradient between Pre-BAP and Post-BAP } \\
\text { in re-CoA group }(p<0.0001),{ }^{* *} \text { comparison of diameter of the CoA } \\
\text { segment between pre-BAP and post-BAP in re-CoA group }(p<0.0001) \text {, } \\
\text { significant, "extremely significant, Na-CoA: native-coarctation of the } \\
\text { aorta, Re-CoA: recoarctation-coarctation of the aorta }\end{array}$} \\
\hline
\end{tabular}

segment by approximately $36 \%$ (from $3.6 \pm 0.5$ to $4.9 \pm 0.7 \mathrm{~mm}, p<0.0001)$. The detailed BAP procedure data is showed in Table 2.

Post procedural complications. There were no mortality, and no threatening events occurred relative to the procedure (namely, aortic dissection, immediate aneurysm, or neurologic complications).

Acute follow-up (day-1 after the procedure). The blood pressure gradients between UL and LL significantly improved; in the $\mathrm{Na}-\mathrm{CoA}$ group decreased from $40.26 \pm 17.58$ pre-BAP to $11.7 \pm 7.9 \mathrm{~mm} \mathrm{Hg}$ post-BAP $(p=0.002)$, and in the Re-CoA group decreased from $35.98 \pm 17.34$ pre-BAP to $10.9 \pm 8.6 \mathrm{~mm} \mathrm{Hg}$ post-BAP $(p<0.0001)$. Similarly, the peak Doppler systolic gradient on 2-dimensional (2D) transthoracic echocardiography significantly decreased in $\mathrm{Na}-\mathrm{CoA}$ (from 56.94 21.49 to $17.8 \pm 9.3 \mathrm{~mm} \mathrm{Hg}, p=0.0008$ ) and Re-CoA (from $47.64 \pm 22.75$ to $15.8 \pm 6.9 \mathrm{~mm} \mathrm{Hg}, p<0.0001)$. 
Mid-term follow-up. The overall mid-term follow-up period was $9.5 \pm 1.6$ months; during which the mean blood pressure gradient between UL and LL, the 2D and the peak Doppler systolic gradient on echocardiography were regularly assessed.

The need for re-intervention after initial BAP occurred in 3 children $(42.8 \%)$ from the $\mathrm{Na}-\mathrm{CoA}$ group ( 2 of them developed re-stenosis [with increased systolic blood pressure gradient between UL and LL $>20 \mathrm{~mm} \mathrm{Hg}$ during the follow-up period] and performed an end-to-end surgical repair, and the third one showed a local aneurysm which was managed by deployment of a covered stent). On the other hand, 5 children (25\%) from the Re-CoA group experienced re-intervention ( 4 of them developed re-stenosis and performed another BAP within 10-12 weeks, and one patient needed a covered stent after development of in-site aneurysm), Figure 2.
Discussion. In this retrospective study, we aimed to report our center's experience, and assess the safety and efficacy of BAP in children for treating $\mathrm{Na}-\mathrm{CoA}$ and Re-CoA according to our center protocol of management. Thus, 7 children was diagnosed to have $\mathrm{Na}-\mathrm{CoA}$, in which 5 of them (2/3 of the group) had an isolated lesion, and this was in disagreement with previous reports which reported an increased incidence of association of $\mathrm{Na}-\mathrm{CoA}$ with other congenital heart disease such as bicuspid aortic valve disease. ${ }^{9}$ On the other hand, this study showed that the incidence of Re-CoA following initial surgical correction represented more than half of the group (12 out of 20 children), in agreement with a previous studies that stated that Re-CoA represent a common complication after surgical correction, with an incidence of 16 up to $60 \% .{ }^{10}$ In our series, the immediate success rate for achieving a residual gradient $\leq 10 \mathrm{~mm} \mathrm{Hg}$ was $71.4 \%$ for $\mathrm{Na}-\mathrm{CoA}$

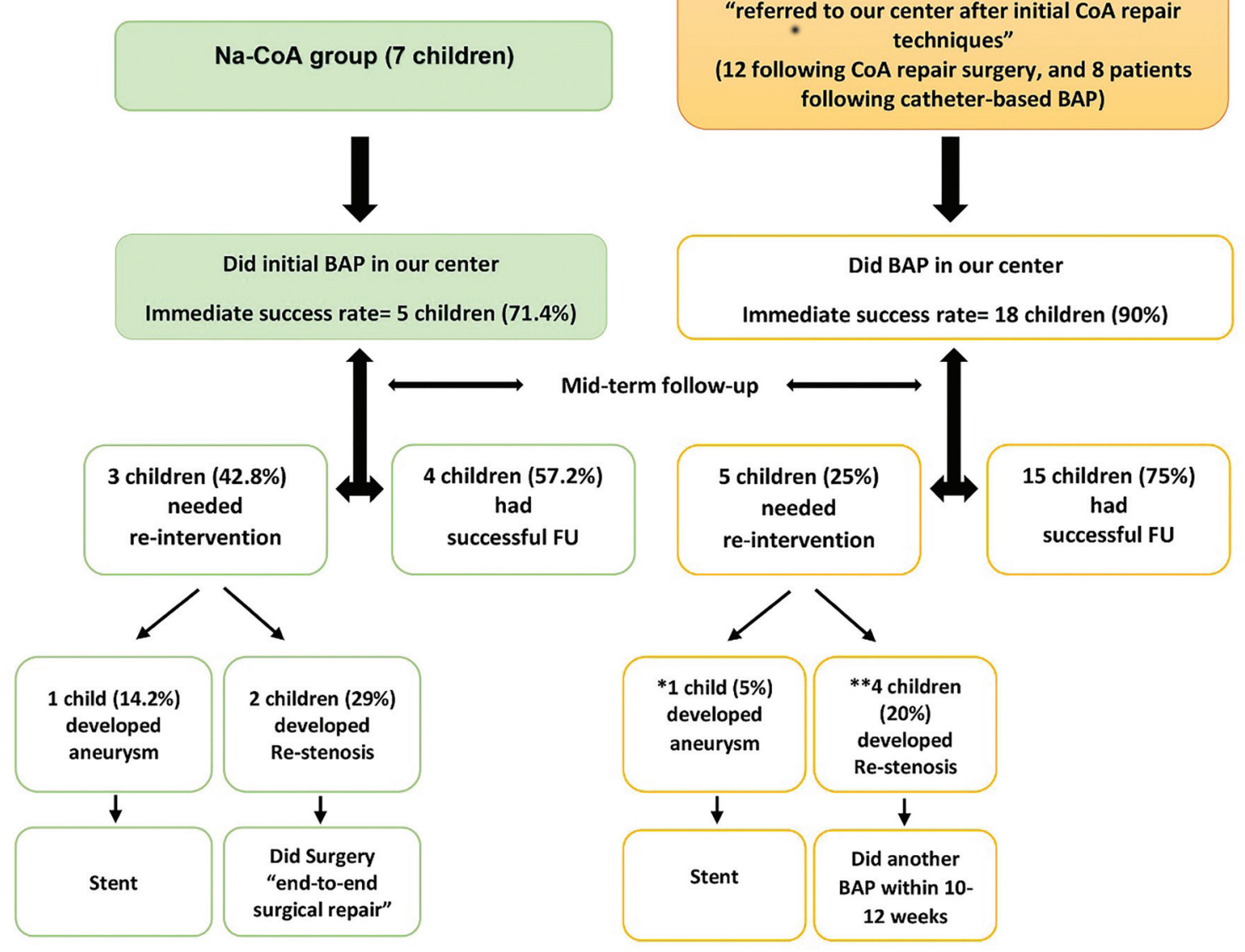

Figure 2 - Detailed management and outcome of the study cohort. *had a balloon angioplasty (BAP) outside our center, ${ }^{* *}$ had an aortic arch patch reconstruction surgery outside our center, Na-CoA: native-coarctation of the aorta, Re-CoA: recoarctation-coarctation of the aorta, FU: follow-up 
group and $90 \%$ for Re-CoA group (mean $85 \%$ of the whole cohort), which is comparable to other cohorts of infants and older children (about 70-90\%)..$^{11-13}$

The immediate results of both study groups are comparable with each other. There was a significant reduction of the mean invasive measured peak systolic pressure gradient across the $\mathrm{CoA}$ segment in both groups $(9.8 \pm 6.5 \mathrm{~mm} \mathrm{Hg}$ in $\mathrm{Na}-\mathrm{CoA}$ group, $10.9 \pm 8.5 \mathrm{~mm} \mathrm{Hg}$ in Re-CoA group, $p=0.7587$ ). An improvement in the mean diameter of the CoA area in both groups occurred (1.4 mm in Na-CoA group and $1.3 \mathrm{~mm}$ in Re-CoA group, $p=0.5193)$. In addition, there was a remarkable improvement in the ratio of diameter of CoA segment to diameter of descending aorta (from 0.53 to 0.74 ) in $\mathrm{Na}-\mathrm{CoA}$ and in $\mathrm{Re}-\mathrm{CoA}$ groups (from 0.55 to 0.74). These achievements are in agreement with the results of previous studies for managing both $\mathrm{Na}-\mathrm{CoA}$ and Re-CoA by catheter based BAP, ${ }^{13,14}$ whereas it disagrees with a study reporting the results for $\mathrm{Na}-\mathrm{CoA}$ management by BAP in neonates and young infants. ${ }^{15}$

There were no serious in-situ complications (namely, mortality, aortic aneurysm or dissection). This was in concordance with recent studies reporting no mortality linked to the procedure. ${ }^{16,17}$

As recently published, the significant mid-term complication following BAP was the recurrence of CoA or the need for re-intervention. The recurrence rate and the need for re-intervention differ considerably between studies, ranging from $6 \%$ to $53 \% .{ }^{17,18}$ Lefort et al described a rate of re-intervention at approximately $35 \%$ after initial angioplasty; ${ }^{17}$ this agrees with our results as we reported a recurrence rate or need for re-intervention in 8 children $(29.6 \%)$ of the total cohort $(n=3 ; 42.8 \%)$ from the $\mathrm{Na}-\mathrm{CoA}$ group, and 5 children $(25 \%)$ from the Re-CoA group, after an initial immediate success rate of $85 \%$ of the whole cohort. By analyzing these results, we found that: i) achieving a residual pressure gradient $<10 \mathrm{~mm} \mathrm{Hg}$ might not be the sole indicator for success of the procedure. ii) also, 2 children (29\%) out of the $\mathrm{Na}-\mathrm{CoA}$ group ended by surgical repair for the lesion, which may raise a concern on the benefit of BAP in $\mathrm{Na}-\mathrm{CoA}$ especially in young infants, and that the surgical option might be recommended for all $\mathrm{Na}-\mathrm{CoA}$ patients who are too small to receive stent therapy. ${ }^{15}$ iii) However, the Re-CoA group had benefit from BAP procedure with a lower incidence of re-intervention ( 5 children [25\%] versus $42.8 \%$ from $\mathrm{Na}$-CoA group). The most surprising finding is that the 4 children from the Re-CoA group who developed re-stenosis and performed repeated BAP; had previously done an aortic arch patch reconstruction surgery, which may raise an inquiry about this type of surgery; ${ }^{19}$ and the remaining fifth child done initially a BAP outside our center.

In the intermediate follow-up period, if suspecting the development of an aneurysm at the site of BAP while screening with the transthoracic echocardiography (TTE); then we potentially refer this patient to do CT angiography. Three patients from the Na-CoA group were suspected and referred to be CT-imaged, and we found aneurysm in one of them $(33.3 \%$ of the suspected, and $14.2 \%$ of the total group); while in the Re-CoA group, 5 patients were suspected and referred for imaging, but only one patient were proved to have an aneurysm (20\% of the suspected and $5 \%$ of the total group). These rates may be underestimated, as we did not perform routinely a CT-angiography during the follow-up period for all the participants. In agreement with our results, other studies reported a higher incidence of developing aneurysm after BAP in $\mathrm{Na}-\mathrm{CoA}$ (approximately 16-24\%), while having a lower incidence in the Re-CoA group (approximately $2-7 \%$ ), most likely because the scar tissue at the site of the previous dilatation prevents aortic wall injury. ${ }^{6,16,20}$

Study limitation. The limitation of our study is that the number of patients was small, in addition to the non-selective inclusion of patients. Also, any missing data may be owed to the retrospective design of the study.

In conclusion, although $\mathrm{BAP}$ is considered as safe procedure for management of CoA, but its efficacy remains questionable especially for young infants with $\mathrm{Na}-\mathrm{CoA}$ type. However, it is a reliable option for managing Re-CoA children, with a lower rate of future re-intervention.

Acknowledgment. The authors would like to thank Madinah Cardiac Center, Madinah, Saudi Arabia, for their cooperation and allowing us to undertake this study. The authors extend their thanks to all the children and their legal guardians who willingly participates in this study. In addition, we would like to thank ThinkSCIENCE Inc. (www. ThinkScience.co.jp) for English language editing.

\section{References}

1. O'Brien P, Marshall AC. Coarctation of the aorta. Circulation 2015; 131: e363-e365.

2 Herzog S, Dave H, Schweiger M, Hübler M, Quandt D, Kretschmar O, Knirsch W. Effectiveness of balloon angioplasty in children with recurrent aortic coarctation depends on the type of aortic arch pathology. J Interv Cardiol 2016; 29: 414-423.

3. Suradi H, Hijazi ZM. Current management of coarctation of the aorta. Glob Cardiol Sci Pract 2015; 2015: 44. 
4 Burch PT, Cowley CG, Holubkov R, Null D, Lambert LM, Kouretas PC, et al. Coarctation repair in neonates and young infants: is small size or low weight still a risk factor? J Thorac Cardiovasc Surg 2009; 138: 547-552.

5. Brown ML, Burkhart HM, Connolly HM, Dearani JA, Cetta F, Li Z, et al. Coarctation of the aorta: Lifelong surveillance is mandatory following surgical repair. J Am Coll Cardiol 2013; 62: 1020-1025.

6. Salcher M, Naci H, Law TJ, Kuehne T, Schubert S, Kelm M, et al. Balloon dilatation and stenting for aortic coarctation: A systematic review and meta-analysis. Circ Cardiovasc Interv 2016; 9: e003153.

7. Brown JW, Ruzmetov M, Hoyer MH, Rodefeld MD, Turrentine MW. Recurrent coarctation: Is surgical repair of recurrent coarctation of the aorta safe and effective?. Ann Thorac Surg 2009; 88: 1923-1930.

8. Galinanes EL, Krajcer Z. Most coarctations, recoarctations, and coarctation-related aneurysms should be treated endovascularly. Aorta (Stamford, Conn) 2015; 3: 136-139.

9. Vergales JE, Gangemi JJ, Rhueban KS, Lim DS. Coarctation of the aorta - the current state of surgical and transcatheter therapies. Curr Cardiol Rev 2013; 9: 211-219.

10. Luijendijk P, Bouma BJ, Groenink M, Boekholdt M, Hazekamp MG, Blom NA, et al. Surgical versus percutaneous treatment of aortic coarctation: New standards in an era of transcatheter repair. Expert Rev Cardiovasc Ther 2012; 10: 1517-1531.

11. Lee CL, Lin JF, Hsieh KS, Lin CC, Huang TC. Balloon angioplasty of native coarctation and comparison of patients younger and older than 3 months. Circ J 2007; 71: 1781-1784.

12. Parra-Bravo JR, Resendiz-Balderas M, Francisco-Candelario R, García H, Chávez-Fernández MA, Beirana-Palencia LG, et al. Balloon angioplasty for native aortic coarctation in children younger than 12 months: immediate and medium-term results. Arch Cardiol Mex 2007; 77: 217-225.
13. Adjagba PM, Hanna B, Miró J, Dancea A, Poirier N, Vobecky $S$, et al. Percutaneous angioplasty used to manage native and recurrent coarctation of the aorta in infants younger than 1 year: Immediate and midterm results. Pediatr Cardiol 2014; 35: 1155-1161.

14. Dilawar M, El Said HG, El-Sisi A, Ahmad Z. Safety and efficacy of low-profile balloons in native coarctation and recoarctation balloon angioplasty for infants. Pediatr Cardiol 2009; 30: 404-408.

15. Liang CD, Su WJ, Chung HT, Hwang MS, Huang CF, Lin YJ, et al. Balloon angioplasty for native coarctation of the aorta in neonates and infants with congestive heart failure. Pediatr Neonatol 2009; 50: 152-157.

16. Harris KC, Du W, Cowley CG, Forbes TJ, Kim DW; Congenital Cardiac Intervention Study Consortium (CCISC). Congenital cardiac intervention study consortium. A prospective observational multicenter study of balloon angioplasty for the treatment of native and recurrent coarctation of the aorta. Catheter Cardiovasc Interv 2014; 83: 1116-1123.

17. Lefort B, Lachaud M, El Arid JM, Neville P, Soulé N, Guérin $\mathrm{P}$, et al. Immediate and midterm results of balloon angioplasty for recurrent aortic coarctation in children aged <1-year. Arch Cardiovasc Dis 2018; 111: 172-179.

18. Torok RD, Campbell MJ, Fleming GA, Hill KD. Coarctation of the aorta: management from infancy to adulthood. World J Cardiol 2015; 7: 765-775.

19. Walhout RJ, Lekkerkerker JC, Oron GH, Hitchcock FJ, Meijboom EJ, Bennink GB. Comparison of polytetrafluoroethylene patch aortoplasty and end-to-end anastomosis for coarctation of the aorta. J Thorac Cardiovasc Surg 2003; 126: 521-528.

20. Hoffman JL, Gray RG, LuAnn Minich L, Wilkinson SE, Heywood M, Edwards R, et al. Screening for aortic aneurysm after treatment of coarctation. Pediatr Cardiol 2014; 35: 47-52. 